\title{
Värvingupartiklite kujunemisloost: saksakeelsete partiklite doch, wohl ning ja eestikeelsed vasted
}

\author{
JANIKA K ̈̈RK \\ Tallinna Ülikool
}

Ülevaade. Uurimus keskendub värvingupartiklite ajaloolis-võrdlevale analüüsile. Otsitakse vastust küsimusele, kas värvingupartiklid on eesti keeles oma ilming või arenenud saksa keele mõjul, kus need on kujunenud adverbidest leksikaalse tähenduse pleekumise ja uue tähendusvarjundi lisandumise teel. Artiklis vaadeldakse eestikeelsete partiklite kujunemist saksa keele taustal. Uuritav ajavahemik hõlmab sada aastat (1632-1732), tekstidena kasutatakse saksa pastorite kirja pandud käsiraamatuid, dialooge ja kiriklikke tekste, mis on kättesaadavad nii eesti kui ka saksa keeles. Saksakeelsete partiklite doch, wohl, ja ning nende eestikeelsete vastete võrdlemisel selgub, et tegemist on pigem kasutusmalli kopeerimise kui otsese laenamisega.

Võtmesõnad: saksa keele mõju eesti keelele; laensõnad; värvingupartiklid; eesti keel; saksa keel

\section{Sissejuhatuseks}

Artiklis vaadeldakse saksa ja eesti keele värvingupartikleid diakroonilisest vaatenurgast. Otsitakse vastust küsimustele, kas saksakeelsed värvingupartiklid omavad vanemas eesti (kirja)keeles vasteid, kas partiklid on oma keele ilming või on saksa keele mõju partiklite kasutamise leksikaalsetele ja semantilistele aspektidele. Kahjuks ei ole artikli autorile 
teada uurimusi partiklite laenamisvõimaluste kohta teistes keeltes - vaid tšehhi keele kohta on oletatud, et kindlasti on saksa mõju olemas, aga kuna värvingupartikleid on tšehhi keeles palju ja neid ei saa üks-üheselt üle võtta, siis on ilmselt tegu oma, st tšehhi keele partiklitega (vrd Karsten 2007).

Saksa keeles on värvingupartiklid kujunenud aja jooksul (peamiselt) adverbidest erifunktsiooni lisandumise teel. Põhiküsimus on, kas saksa- ja eestikeelseid paralleeltekste võrreldes võib midagi väita ka eesti keele värvingupartiklite kujunemise kohta: milliseid värvingupartikleid leidub saksa pastorite 17. ja 18. sajandil tekstides, millistes funktsioonides uuritavad sõnad esinevad ja kas on võimalik selgitada, kas partiklite kandumine saksa keelest eesti keelde, on olnud nende kahe keele paralleelse kasutamise vältel produktiivne ning millal ja mis tingimustes võis partiklite laenamine toimuda.

Uurimus keskendub peamiselt eesti kirjakeele kujunemise esimesele perioodile, mil saksa keel oli dominantne ja eesti keele prestiiž madal. Saksa keeles domineeris ülemsaksa keel, kuigi argikeelena oli veel kasutusel ka alamsaksa keel. Alates 18. sajandi algusest eristatakse eestlaste ja sakslaste eesti keelt (vrd Hennoste 1997). Uurimuse aluseks olevad tekstid on kirja pannud sakslased, sooviga hõlbustada saksa pastorite tööd ristiusu kinnistamisel eesti rahva hulgas. Põhieesmärk oli eestlaste mõjutamine. Kuna kõnealused värvingupartiklid väljendavad lauses kõneleja suhtumist, võivad partiklid olla üks mõjutamisvahendeid. Nii näiteks mõjub värvingupartiklit $j u$ sisaldav etteheide intensiivsemana kui ilma partiklita (1).

(1) Ma ju käskisin tähelepanelikult kuulata! Ma käskisin tähelepanelikult kuulata!

Seega võivad saksa pastorite kirja pandud tekstid olla tänuväärne allikas lause pragmaatilist funktsiooni kandvate (värvingu)partiklite uurimisel.

Partikleid leiab ka vanimates kirjalikes eestikeelsetes allikates, kuid sel juhul on tegemist pigem üksiksõnadega, heal juhul lausekatketega, mis ei paku piisavat alust partiklite analüüsiks. Tartu Ülikooli vana kirja- 
keele korpuse vanimate tekstide (13.-16. sajand) märksõnade sagedusloendi analüüs andis tulemuseks neli partiklit: ei (3 esinemisjuhtu), küll (2), koguni (1) ja päinis (1). Georg Mülleri jutlustes (1600-1608) esineb partikleid arvukamalt: $k a$ (1101), mitte (1008), päinis (201), äranis (173), tõesti (172), veel (158), küll (117), ju (87), doch (44), kummatigi (36), vägasti (30), pealegi (12), ei (9, peamiselt ei siis...), väga (9), aga (8), paraku (8), nämlich (1). Ka Turu käsikiri 17. saj I poolest sisaldab partikleid küll (2), siiski (2) ja Rossihniuse kirikuraamatust võib leida partiklid mitte (642), tõelikult (63), küll (53), doch (21), kummatigi (14), muidu (10), ju (2), las (2) ja äranis (1). Siinkohal vajab täpsustamist, et eespool toodud loetelus on nimetatud kõik sagedusloendis esinevad modaalses tähenduses kasutatud sõnad, eristamata nende seas värvingupartikleid kitsamas tähenduses. Ka sõnade kirjaviis võib varieeruda.

Käesolevas artiklis keskendutakse kolmele enamlevinud saksakeelsele partiklile doch, ja, wohl ning nende eestikeelsetele vastetele.

\section{2. Ülevaade materjalist}

Partiklite doch, wohl ning ja kasutamist on analüüsitud järgmistest tekstidest koosneva korpuse alusel:

1) Heinrich Stahl "Hand- und Haußbuch" (HH) I ja II 1632-1637; osad III ja IV 1638;

2) Heinrich Stahl "Leyen Spiegel” (LS) 1641-1649;

3) Christoph Blume "Das Kleine Corpus Doctrinae" 1662, "Geistliche Wochen-Arbeit" 1666, "Geistliche Hohe Fäst-Tahgs Freude" 1667 (Bl);

4) Anton Thor Helle "Anweisung zur Ehstnischen Sprache" 10 dialoogi 1732 (AzES). ${ }^{1}$

Heinrich Stahli "Hand- und Haußbuch" on paralleelselt saksa ja eesti keeles kirjutatud käsiraamat, mis ühendab endas misjonikirjanduse eri

Tekstid on võetud Tartu Ülikooli vana kirjakeele korpusest, vt http://www.murre. ut.ee/vakkur/korpused.htm (14.07.2012). 
tahke: kirjaoskamatule talurahvale mõeldud lihtsa katekismuse, käsiraamatu vaimulikele ja abivahendi koduseks palvetamiseks. Otsest eeskuju, mida kopeerida, Stahlil tõenäoliselt ei olnud, kuigi Saksamaal oli ilmunud sarnaseid käsiraamatuid ohtralt (P. Lotman 2010: 115). Stahli tekstid ja grammatikaseisukohad kujutasid endast 17. saj Põhja-Eesti kirjakeele senise arengu kokkuvõtet ja edasiarendust, millega tahes-tahtmata arvestasid järgnevad kirjamehed (vrd Laanekask 2004: 21). Ühest küljest põhines Stahli keelekujunduslik tegevus humanistlikel ideedel, mis soosisid toetumist talurahvakeelele, teisalt oli tema tegevus kantud misjonilingvistikale omasest veendumusest, et rahvakeele väljendusvõimalusi võib ja peab muutma oma äranägemist järgi (vrd Laanekask 2004: 20).

Pea kümme aastat hiljem ilmunud jutlustekogu "Leyen Spiegel" koosneb Lutheri eeskujul suve- ja talveosast, adressaadiks mh teoloogiateaduskonnad. "Tema [Stahli] jutlused mõjuvad poeetiliste ja jõulistena ning ülimalt emotsionaalsetena. Siiski on eestikeelne tekstiveerg kaunis abitu ja segane, keeleliselt ebaühtlane ja kohmakas ning raskesti mõistetav" (Lotman 2010: 137).

Hageri pastori Christoph Blume vaimulike paralleeltekstide sisuks on palved, katekismuse seletused ja muud kirikuaastaks mõeldud tekstid. Võrreldes Stahliga toob Blume sisse terve hulga uuendusi: loobutud on saksapärasest eitusest, määrava artikli tõlkimisest, ei ühildata asesõnalist täiendit jm (Laanekask 2004: 24). Eeskuju on Blume võtnud varasematest kirjakeele tekstidest ja rahvakeelest, kuid ta on loonud sõnu ka analoogia põhjal (Lill 1988: 102).

Anton Thor Helle, Jüri kihelkonna pastori põhjaeestikeelne keeleõpetus "Kurtzgefaßte Anweisung zur Ehstnischen Sprache" paistab silma hea eesti keele oskuse poolest ning on talupoegade sõnade järgi üles tähendatud (Helle 2006: 10 [1732]).

Eespool kirjeldatud tekstid on valitud põhimõttel, et iga tekst oleks kättesaadav nii saksa kui ka eesti keeles. Seetõttu on materjali valik teatud mõttes ebaühtlane, kuid mitte suvaline, mis lubab teha tähelepanekuid partiklite kasutamise kohta saja aasta vältel (1632-1732), kuid ei võimalda võrrelda partiklite kasutamisega seotud pikemaajalisi muutusi. 
Analüüsitud neljas tekstis oli partiklite doch, wohl ning ja kasutusnäiteid kokku 1114 saksa- ja eestikeelset lausepaari (vt tabel 1).

TABEL 1. Saksa- ja eestikeelsed lausepaarid partiklitega doch, wohl ning ja

\begin{tabular}{|l|c|c|c|}
\hline Tekst & doch & wohl & ja \\
\hline $\begin{array}{l}\text { Stahl “Hand- und } \\
\text { Haußbuch" }\end{array}$ & 145 & 132 & 73 \\
\hline Stahl "Leyen Spiegel” & 284 & 210 & 146 \\
\hline Blume & 15 & 8 & 19 \\
\hline Helle "Anweisung..." & 6 & 49 & 27 \\
\hline
\end{tabular}

\section{Partikli mõiste ja värvingupartiklid}

Partikleid käsitletakse saksa keeleteaduslikus kirjanduses laiemas ja kitsamas tähenduses. Esialgu kasutati seda mõistet kõigi muutumatute sõnade tähistamiseks (DUDEN 1966: 67). Viimastel aastakümnetel on see arusaam teinud läbi olulise arengu: räägitakse partiklilisusest kui adverbi erifunktsioonist (Thurmair 1989: 8; Helbig, Buscha 1996: 495-498; Eisenberg 1985: 208), alates 20. saj lõpust muutub valdavaks seisukoht, et partiklid eristuvad adverbidest sõltumatu iseseisva sõnaliigina (DUDEN 2009: 588-599; Helbig, Buscha 2001: 419). Kõige kitsamas tähenduses on saksakeelses teaduskirjanduses terminiga partikkel tähistatud modaalpartikleid (sks Modal-, Abtönungspartikeln), mille eestikeelse vastena on Tiit Hennoste pakkunud mõiste värvingupartiklid (Hennoste 2000: 1804) $)^{2}$.

Harald Weydt, vast kõige rohkem partikleid uurinud keeleteadlane Saksamaal, peab oluliseks järgmisi tunnuseid: partiklid on muutumatud sõnad, mis ei saa esineda iseseisva lauseliikmena; nende leksikaalne tähendus on tuhmunud; partiklid kuuluvad teatavate lauseliikmete juurde, modifitseerivad nende tähendust ja tõstavad neid esile, väljenda-

2 Põhjalikum ülevaade mõiste kujunemisloost vt Kärnä 2005. 
vad millegi intensiivsust ning edastavad kõneleja (kirjutaja) suhtumist (Hentschel, Weydt 1994: 246). Tavaliselt esinevad partiklid ilma rõhuta, moodustades koos täistähendusliku sõnaga, mille juurde nad kuuluvad, süntaktilise terviku.

Nii eesti- kui ka saksakeelses partikliuurimise traditsioonis on välja toodud erinevaid partikliliike (värvingu-, modaal-, intensiivsusja kraadi- ehk fookuspartiklid), mis käituvad lauses mõneti erinevalt ning kannavad vastavale partikliliigile omast pragmaatilist funktsiooni. Teatavasti võivad mitmed sõnad esineda nii adverbina kui partiklina, samuti võib üks partikkel vastavalt funktsioonile lauses kuuluda erinevatesse partikliliikidesse. Adverbi ja partikli eristamisel on siinkohal lähtutud põhimõttest, et adverb on iseseisev lauseliige, millel on oma kindel süntaktiline funktsioon. Partikli võib lauses ära jätta, ilma et lause muutuks grammatiliselt valeks või kaoks osa semantilist informatsiooni, nt adverb - Siis (ajamäärus) läksime koos kinno; partikkel - Ja siis see hädaldamine!

Kui saksakeelses teaduskirjanduses mõistetakse terminite Modalpartikeln ja Abtönungspartikeln (ka Einstellungspartikeln, Satzpartikeln) all ühte ja sama partiklirühma, siis eristab Tiit Hennoste (2002: 60-61), Auli Hakulineni muutumatute sõnade tüpoloogiale ja Longmani grammatika tüpoloogiale toetudes ühelt poolt värvingupartikleid kui lauset "värvivaid" ja teisalt modaalpartikleid kui kõneleja suhtumist väljendavaid partikleid, paigutades mõlemad vabalt liikuvate tekstipartiklite hulka. Vastupidiselt piiripartiklitele paiknevad vabalt liikuvad tekstipartiklid lausungite sees ja võivad seal vabamalt liikuda. Hennoste nimetab Eesti sagedasemate värvingupartiklitena ikka, nüüd, sis, alles, küll, eks, tõesti, just, õige, alati, vaid, ju muidugi?, tegelt?, ütleme?, -gi/-ki. Modaalpartiklid osutavad kõneleja arvamusele või käsitusele kõnealuse olukorra tõenäosuse, kindluse või vältimatuse kohta, esindades seega episteemilist modaalsust, nt vist, muidugi, kindlasti, loomulikult, ehk, kuuldavasti, vaevalt, võibolla, küllap jms (Hennoste 2000: 1803-1805). 
Artiklis vaadeldavad värvingupartiklid on muutumatud sõnad, mis edastavad kõneleja emotsioone, suhtumist, ootusi jm ning esinevad lauses süntaktiliselt sõltumatult, st neid on võimalik lausest välja jätta, ilma et lause muutuks grammatiliselt valeks. Värvingupartiklid lisavad lausele mitmeid semantilisi ja pragmaatilisi varjundeid, tihti sõltuvalt lauseliigist. Uurimuse materjali arvestades ei ole värvingupartiklite funktsiooni eristamine vastavalt lauseliigile otstarbekas, kuna valdavalt on tegu väitlausetega.

\section{Saksakeelsete partiklite doch, wohlning ja eestikeelsed vasted}

\subsection{Partikkel doch}

Esimesena vaadeldakse partiklit $d o c h$, mis on tänapäevases saksa kõnepruugis enimlevinud partikkel.

Algselt esines doch keskalamsaksa keeles sidesõna ja adverbina tähenduses 'dennoch' ('siiski') ja 'obwohl' ('kuigi') (Hentschel 1986: 5). Praeguseks on lisandunud mitmeid tähendusvariante, nagu kinnitus, identifitseerimine, esile tõstmine ning rõhutamine. Doch võib tähistada ka eitust, vastandlikkust (Ormelius-Sandblom 1997: 72) või toimida korrigeerijana (Thurmair 1989: 109). Niisiis omab partikkel doch nii kinnitavaid kui ka vastandavaid tähenduskomponente. Harald Weydti (1979: 397) sõnul eristub doch teistest partiklitest, kuna eeldab konsensuse olemasolu, st näitab, et kõnetataval on vastav informatsioon olemas. Jutta Lütten (1979: 32) lisab veel ühe olulise semantilise komponendi: nimelt esinevat doch enamasti lausungites, mis väljendavad isiklikku olukorda ja nimelt seotuna verbidega nagu uskuma, arvama, leidma, mõtlema, oletama.

Kui vanaülemsaksa keeles (600-1050) oli doh/thoh peamiselt kasutusel lause alguses adversatiivse ehk vastandava konjunktsiooni funktsioonis või adverbina, siis värvingupartiklina esineb doh/thoh ka lause keskel, eriti üleskutsetes, muutes käsu või palve tungivamaks. Keskülemsaksa keeles (1100-1350) on täheldatud värvingupartikli doch kasutuse 
kasvu, eriti otseses kõnes. Juba 14. saj teisest poolest ei ole partikli doch kasutamises märkimisväärseid erinevusi praegusega võrreldes (vrd Fritz 2005: 228).

Stahli vanemates tekstides esineb peamiselt partikli doch kolm kasutusvarianti. Valdavalt on saksakeelne partikkel otse üle kantud eestikeelsesse lausesse (näited 2 ja 3). Kokku 150 partikli doch esinemisnäites on tervelt 85 puhul tegemist sama sõna kordamisega mõlemas keeles.

(2) On tema doch sünnul omal ajal / öhes silmapilgmisses sünno hinge ninck iho / ninck kahs se ajalicko ello / ilma sünno waiwa / murre ninck töh / emma iho siddes andnut.

Hat er dir doch zu seiner Zeit / im augenblick dein Seel vnd Leib / vnd das Natürlich Leben / ohn all dein müh / sorg / vnd arbeit / in Mutter Leib gegeben. (HH 1637: 98)

(3) tema pajatap / nüdt on keick erra kaddout / kus doch se rist on ühest sündinut / kumbat sünno abbi ohtwat.

Sie spricht: Es ist nun alls verlohrn / da doch das Creutz hat new geborn / die deiner Hülff erwarten. (HH 1637: 141)

Teiseks on partikli doch vastena kasutatud eestikeelset adverbilaadset partiklit sihskit tähenduses 'ometi,' 'ikkagi' (4) või 'sellest hoolimata' (5).

(4) Sihs sahwat nemat sihskit tundma / eth sinna meije Jummal ellat weel / ninck awwitat weggiwast omma koggodusse / kumb üx peines sünno pehle lohtap.

So werden sie erkennen doch / daß du vnser Gott lebest noch / vnd hilfst gewaltig deiner Schaar / die sich auff dich verlassen gar. (HH 1637: 143)

(5) Echk kül se ilm ninck keick kurratit / sesinnases paigkas / öhes hulckas seisaxit / sihskit on sünno jures röhm ninck arm / Jssand JEsu Christ / sinna woit nemmat üllewoidma /

Wenn schon die Welt vnd Teuffel all / in diesem Thal / auffeinen hauffen stünden / so ist doch bey dir Trost vnd frist / HERR JEsu Christ / du kanst sie vberwinden. (HH 1637: 120)

Õnnestus leida ka paar näidet, kus saksakeelses lauses partiklit doch ei kasutata, kuid paralleelses eestikeelses lauses on see olemas (6). 
(6) Se suhremb hulck sünd Jssand pölgkap / sünno sanna minxix pannep / echk meije kül tahaxime omma wehje kahs / woime meije doch neil mitte keelma / semperrast meije se pehle lohtame / eth sinna ep saht n[en]de pattude perrast $O$ Jssand meid mitte nuchtlema.

Der gröste hauff dich / HErr / verachtet / sich an dein Wort nicht kehret / ob wir gleich wollen mit vnser Macht / können wir jhnen nicht wehren / seind wir darumb in zuversicht / du werdest vns HERR / lassen nicht / jhrer bößheit entgelten. (HH 1637: 116)

Sihskit kasutab partikli doch vastena Stahl oma "Hand- und Haußbuch" veergudel 26 korda 150-st. Tundub, et Stahl on veendunud partiklikasutamise vajaduses eestikeelsetes tekstides, sest vaid 37 juhul 150-st on eestikeelses lauses partikkel doch tõlkimata jäänud.

Sarnaselt kasutab Stahl partikleid ka pea 10 aastat hiljem kirjutatud raamatus "Leyen Spiegel” (1641-1649). Ka siin on valdavaks saksakeelse partikli doch üle kandmine eestikeelsesse lausesse (vt tabel 2). Üle poolte saksakeelses tekstis esinevatest partiklitest kordub samal kujul ka eestikeelses tekstis. Märkimisväärne vähenemine (25\%-lt 9\%-le) on toimunud neil juhtudel, kus saksakeelne partikkel on eesti keeles jäänud üldse tõlkimata. Ilmselgelt peab Stahl partiklite kasutamist eesti keeles tähtsaks. Peamiseks uuenduseks "Leyen Spiegelis" on eestikeelse kumbatakit esinemine saksakeelse partikli doch vastena. Siinkirjutaja tõlgendaks seda tänapäevase adverbiga kummatigi, mis nüüdisajal väljendab 1. 'ometi', 'siiski'; 2. 'ammuks siis', 'saati siis'; 3. 'lisaks kõigele', 'pealegi' (EKSS).

TABEL 2. Saksakeelse partikli doch vasted eesti keeles (Stahl)

\begin{tabular}{|l|c|c|c|c|c|}
\hline Tekst & doch/doch & $\begin{array}{c}\text { doch/ } \\
\text { sihskit }\end{array}$ & doch/- & -/doch & $\begin{array}{c}\text { doch/echk kül, } \\
\text { kumbatakit }\end{array}$ \\
\hline $\begin{array}{l}\text { "Hand- und } \\
\text { Haußbuch" } \\
\text { (kokku 150) }\end{array}$ & $85(57 \%)$ & $26(17 \%)$ & $37(25 \%)$ & $2(1 \%)$ & - \\
\hline $\begin{array}{l}\text { "Leyen } \\
\text { Spiegel" } \\
\text { (kokku 310) }\end{array}$ & $190(61 \%)$ & $60(19 \%)$ & $27(9 \%)$ & $3(1 \%)$ & $30(10 \%)$ \\
\hline
\end{tabular}


Kuigi partikli doch esinemisjuhtude arv Stahli raamatutes "Hand- und Haußbuch" ning "Leyen Spiegel” teineteisest oluliselt erineb, võib siiski järeldada, et Stahl jättis eesti keeles järjest vähem saksakeelseid partikleid doch vasteta ning ilmselt tänu eesti keele oskuse paranemisele lisandus partiklile sihskit veel kumbatakit (7), ühel juhul ka echk kül, mida Stahl muidu kasutab sidesõna obwohl, obgleich, obschon vastena tähenduses 'kuigi'.

(7) Kus se mitte sündip se sinnase ello sees / peap se kumbatakit wissist sündima se töise ello sees.

Geschicht es nicht im diesem Leben / sol es doch gewiß geschehen in jenem Leben. (LS 1641: 161)

Tänapäevaste tekstide analüüs andis saksakeelse värvingupartikli doch vasteteks eesti keeles peamiselt ju, harvem ometi ja siis (vrd Kärk 2010b). Stahl ei ole nimetatud eestikeelseid partikleid kasutanud, kuigi see sisuliselt oleks võinud sobida (8).

(8) Sihs ütlis se Jnnimenne: Se on [ju] luh / münno Luhst / ninck Leeha / münno Lehast / temma sahp meehe Naine Kutzotut sama / semperrast eth temma sest meehest on wottut.

Da sprach der Mensch / das ist doch Bein von meinen Beinen / vnd Fleisch / von meinem Fleisch / man wird sie Maninne heissen / darumb / das sie von dem Manne genommen ist. (HH 1632: 32)

Kokkuvõtvalt võiks öelda, et eestikeelsete partiklite kasutamises on Stahl ebajärjekindel, mis kahtlemata viitab tema puudulikule keeleoskusele. Siiski on Stahl olnud veendunud partiklite tõlkimise vajadusest, millest annab tunnistust kasvav eestikeelsete partiklite variatiivsus.

Põhja-Eesti Hageri pastori Blume teostes leidub võrreldes Stahli kirjapanduga hulk uuendusi, kuid need ei puuduta partikli doch kasutamist, mis on samalaadne Stahli tekstidest leituga. Kokku on 14 lausepaari, partiklit doch on eestikeelses lauses kasutatud 11 korral (9), ühel juhul esineb sihskit (10) ja kahel juhul kummatik (11). 
(9) On doch Jnnimenne otze kud mittakit / temma Aik lehp möda kud üx Warri.

Js[t] doch der Mensch gleich wi nichts / seine Zeit f[ä]ret [da]hin wi ein Schatte. (Bl 1662: 145)

(10) Sihskit tahan Minna hendes Hallestama Juda Koddo pehl nink tahan nemmat awwitama Jssanda nende Jummala lebbi / Minna ep tahan nemmat aggas mitte awwitama / Ambo / Möhka / Södda / Hobbose echk Rütlide lebbi.

Doch wil Jch mich erbarmen über das Haus Juda und wil inen helffen / durch den HErrn iren GOtt / Jch wil inen aber nicht helffen durch Bogen / Schwerd / Streit / Ros oder Reuter. (Bl 1662: 137)

(11) Kus nemmat kummatik Usko seest tullewat nink Öikedusse Wiljat ommat.

Da si doch aus den Glauben hehr kommen und der Gerechtigkeit Früchte sind. (Bl 1662: 119)

Erinevused võrreldes Stahli ja Blumega ilmnesid aga Helle sada aastat hilisemas tekstis. Pietistlikest taotlustest (rahvakeelsus, ühtsus ja selgus) kantud Helle kasutab oma paralleeltekstis "Anweisung zur Ehstnischen Sprache" ainult eesti keelest pärit partikleid. Saksakeelse partikli doch vastena esineb imestust intensiivistav ommeti (12) ja juba eespoolt tuttav, kirjapildis saksa mõju minetanud siiski (13).

(12) Nenda Jummal parrago se tö hukka lääb, mis sa nüüd moisa wiid, ja misga sa ennast ja omma perre kattad? agga kust se ommeti tulleb, et nemmad nenda hukka läinud?

GOtt erbarme sichs! so geht die Arbeit zu nichte! was wilt du nun nach dem Hofe bringen, und womit wirst du dich un dein Gesinde kleiden? Aber woher komt es doch, daß es so zu nichte gangen? (AzES 1732: 388)

(13) Kuida siis? näikse silmaga, kuida noremad surrotakse takka toito otsima, ja ei lähhä siiski kaugele, ja on saggedad käima, kui wihma ook tulleb; kui ook lähhäb ülle, pärris-maia mehhed lähhäwad kaugele, tullewad surema koormaga.

Wie anders? Man siehts mit Augen, wie die Jungen werden nachgetrieben nach der Nahrung auszugegehn, welche doch nicht weit gehen, 
gehen aber eilig wenn ein Regenschauer kommt: ist der Schauer vorüber, so gehen die rechte Bienen weit, und kommen mit grösserer Ladung zurück. (AzES 1732: 403)

Tähelepanuväärne on see, et Helle ei kasuta enam eestikeelses tekstis saksa partiklit doch, nagu seda tegid Stahl ja Blume sada aastat varem, vaid on sellele leidnud eestikeelsed vasted, mis väljendavad samasugust pragmaatilist funktsiooni. Neljal juhul on saksakeelne partikkel doch jäänud vasteta (vt tabel 3).

TABEL 3. Saksakeelse partikli doch vasted eesti keeles (Blume ja Helle tekstide võrdlus)

\begin{tabular}{|l|c|c|c|c|c|}
\hline Tekst & $\begin{array}{c}\text { doch/ } \\
\text { doch }\end{array}$ & $\begin{array}{c}\text { doch/ } \\
\text { sihskit }\end{array}$ & $\begin{array}{c}\text { doch/ } \\
\text { kummatik }\end{array}$ & $\begin{array}{c}\text { doch/ } \\
\text { ommeti }\end{array}$ & doch/- \\
\hline $\begin{array}{l}\text { Blume } \\
\text { (kokku 15) }\end{array}$ & 12 & 1 & 2 & - & - \\
\hline $\begin{array}{l}\text { Helle } \\
\text { (kokku 6) }\end{array}$ & - & $\begin{array}{c}(\text { siiski) } \\
1\end{array}$ & - & 1 & 4 \\
\hline
\end{tabular}

Ilmselgelt on saksakeelne värvingupartikkel doch olnud osa kiriku-, mitte rahvapärasest eesti keelest. Vaatamata ohtrale kasutamisele (Mülleri, Rossihniuse, Stahli ja Blume kirjavaras) ei ole doch muutunud laensõnaks. Ilmselt on eesti keele oma sõnavara pakkunud piisavalt võimalusi saksapärase partikli asendamiseks. Sarnasele tõdemusele jõuab ka Külli Habicht, kes on analüüsinud Stahli episteemilisi ja emfaatilisi modaaladverbe (Habicht 2009). Oletada võib, et saksakeelse partikli doch kasutamise rohkus ärgitas tolle aja kirjamehi ka eestikeelseid partikleid rohkem kasutama. Ühele partikli doch olulisele tähendusvarjundile, nimelt 'ühine teadmine' ei ole Stahl, Blume ega Helle osanud vastet eesti keeles leida, kuigi partikkel jo oli neile kõigile ilmselt tuttav.

Siiski ei ole sama tendents täheldatav teiste partiklite juures. Võtkem vaatluse alla saksakeelse partikli wohl. 


\subsection{Partikkel wohl}

Etümoloogiliselt pärineb alamsaksa wol[e] indogermaani tüvisõnast wollen ('tahtma') ja tähendab 'nii nagu soovitud', esinedes alates 15. saj ka nimisõnana Wohl ('heaolu') (DUDEN Herkunftswörterbuch 1989: 818). Värvingupartikkel wohl edastab teavet selle kohta, et kõneleja peab lausungit tõenäoliseks.

Partikli wohl eestikeelsete vastete analüüsimisel Stahli tekstides joonistub välja selge muster: adverbi funktsioonis esineb wohl saksa keeles tähenduses 'hästi'; eesti keeles on kasutatud adverbi wohl vastetena hehste (heste) (14) või öigkest (15).

(14) Sinna peat omma Jssa / ninck emma auwustama / eth sünnul hehste keip / ninck sinna kouwe ellat mah pehl.

Du solt deinen Vater vnd Mutter Ehren / das diers wol gehe / vnd du lange lebest auff Erden. (HH 1632: 2)

(15) Oppe meid se Jssa öigkest tundma / ninck kahs Jesum Christum temma poja / eth meije sest usckust sahme töiet / sünd mollembade waimo öigkest moistada.

Lehr vns den Vater kennen wol / darzu JEsum Christ seinen Sohn / das wir deß glaubẽs werden voll / dich beyder Geist recht zu verstahn. (HH 1637: 47)

Kui välja jätta umbes kolmandik nii adverbiaalses tähenduses kui ka värvingupartikli funktsioonis kasutatud sõna wohl näidetest, mis eestikeelset vastet ei oma (16), siis on Stahl adverbi wohl tõlkimisel kasutanud järjekindlalt adverbi hehste (mõnel üksikul juhul ka önis/öigkest) ja partikli wohl puhul partiklit kül (17). Sarnaselt ka "Leyen Spiegelis" (vt tabel 4).

(16) Jssand wotta münd omma hohle sisse / ninck kehna münnust erra / lebbi sünno Jummalicko auwo / münno hedda ninck risti / Jssand sinna moistat / mea se on.

HErr laß mich dir befohlen seyn / vnd wend von mir / durch dein Göttliche Zier / das Creutze mein / HERR du weist wol / was es mag seyn. (HH 1637: 114) 
(17) Jummala Rickus tullep kül ilma meddi palwetta / issi hendessest: Agkas meije pallume sesinnase palwe sees / eth temma kahs meite jure tulckut. GOttes Reich kompt wol ohn vnser Gebet von jhm selbst: Aber wir bitten in diesem Gebet / das es auch zu uns komme. (HH 1632: 17)

TABEL 4. Saksakeelse partikli wohl vasted eesti keeles (Stahl)

\begin{tabular}{|l|c|c|c|c|c|}
\hline Tekst & $\begin{array}{c}\text { wol/ } \\
\text { hehste } \\
\text { (heh) }\end{array}$ & $\begin{array}{c}\text { wol/ } \\
\text { öigkest }\end{array}$ & wol/önis & $\begin{array}{c}\text { wol/kühl } \\
(\text { kül) }\end{array}$ & wol/- \\
\hline $\begin{array}{l}\text { "Hand- und } \\
\text { Haußbuch" } \\
\text { (kokku 132) }\end{array}$ & $\begin{array}{c}52 \\
(39 \%)\end{array}$ & $\begin{array}{c}4 \\
(3 \%)\end{array}$ & $\begin{array}{c}5 \\
(4 \%)\end{array}$ & $\begin{array}{c}31 \\
(23 \%)\end{array}$ & $\begin{array}{c}40 \\
(30 \%)\end{array}$ \\
\hline $\begin{array}{l}\text { "Leyen } \\
\text { Spiegel" } \\
\text { (kokku 210) }\end{array}$ & $\begin{array}{c}102 \\
(49 \%)\end{array}$ & $\begin{array}{c}\text { (ka magkus, } \\
\text { kaunist) } \\
3 \text { (3\%) }\end{array}$ & $\begin{array}{c}\text { (ka onnis, } \\
\text { onnis, önsat) } \\
15(7 \%)\end{array}$ & $\begin{array}{c}49 \\
(23 \%)\end{array}$ & $\begin{array}{c}41 \\
(40 \%)\end{array}$ \\
\hline
\end{tabular}

Kõrvalmärkusena huvitav näide, mille põhjal võib aimu saada vastavuse wohl - hea küll tekkelugu (18):

(18) Nemmat pajatasit temma wasto : Ja / kül.

Sie sprachen zu jhm / Ja wol. (HH 1638: 194)

Ka Blume on läbivalt tõlkinud adverbi wohl eestikeelse adverbiga hehsti (19) ja partiklit wohl eestikeelse partikliga kül (20).

(19) Meile on üx kindel Propheti Sanna nink teije teete hehsti / et teije sedda tehhale pannete / kud öhe Kühnla kumb paistap öhes pimmedas Paikas kunni Pehw koitap nink homikko Techt tousep teije Süddamede sees.

Wir haben ein festes prophetisches Wort und ihr tuht wohl / das ihr darauf achtet / als auf ein Liecht das da scheinet in einen tunkkeln Ohrt biß der Tag anbrech [e] und der Morgen-Stern aufgehe in euren Hertzen. (Bl 1662: 21)

(20) Kus doch CHristus ütlep : se on minno Jho nink Werre / Kahs temma MeeleWald nink Weggi sedda kül ( tehha) woip.

Da doch CHRistus saget : Das ist mein Leib und Bluht / auch dessen Gewalt und Kraft solches wohl vermag. (Bl 1662: 115) 
Helle tekstis esineb wohl enamasti värvingupartikli funktsioonis: rõhutatakse, et kõneleja on veendunud kõnealuse teema õigsuses või peab seda väga tõenäoliseks. Helle kasutab eesti keeles mittetemporaalses tähenduses partikleid siis (21), kül ning küllab (22).

(21) Et palluge Jummalat, öppige ja kuulge temma sanna, ja ärge torkuge pattudega Jummala wasto; ehk teie siis woiksite ka sedda usko sada.

Ey, bittet GOtt, lernet und höret sein Wort, und strebet nicht wider GOtt mit euren Sünden; so würdet ihr wol auch den Glauben überkommen. (Helle 1732: 378)

(22) Küllab se teäta, et tö ei löppe ellades perrest ärra, ommeti on hinge murre keige üllem tö.

Das weiß man wol, daß es im Hause niemaln an Arbeit fehlt, indessen bleibt die wichtigste Sorge immer für die Seele. (AzES 1732: 375)

Umbes kolmandikul esinemisjuhtudest on Hellel saksakeelne wohl ka vasteta jäänud. Võrreldes Blumega puudub Helle tekstis adverb hehste (omadussõna heh), värvingupartikli tõlkimisel esineb kül või on partikkel vasteta jäänud (vt tabel 5 ja näide 23).

TABEL 5. Saksakeelse partikli wohl vasted eesti keeles (Blume ja Helle tekstide võrdlus)

\begin{tabular}{|l|c|c|c|c|c|}
\hline Tekst & $\begin{array}{c}\text { wol/hehsti } \\
\text { (heh) }\end{array}$ & $\begin{array}{c}\text { wol/kül } \\
\text { öiete }\end{array}$ & $\begin{array}{c}\text { wol/kühl (kül, } \\
\text { küllab) }\end{array}$ & wol/- & wol/siis \\
\hline $\begin{array}{l}\text { Blume } \\
\text { (kokku 8) }\end{array}$ & $4(50 \%)$ & - & $4(50 \%)$ & - & - \\
\hline $\begin{array}{l}\text { Helle } \\
\text { (kokku 49) }\end{array}$ & - & $1(2 \%)$ & $29(59 \%)$ & $17(35 \%)$ & $2(4 \%)$ \\
\hline
\end{tabular}

(23) Ei ka, temmal on sant pea.

Auch wol nicht, sie hat einen stumpfen Kopf. (AzES 1732: 78)

Tuleb siiski silmas pidada, et analüüsi aluseks võetud Helle "Anweisung" on oluliselt lühem Stahli materjalidest. 
Kõigis analüüsitud tekstides on saksakeelse värvingupartikli wohl vastena eesti keeles kasutatud partiklit küll. Julius Mägiste (2000) andmetel võib oletada et eestikeelne küll on läänemeresoome päritolu adverb tähenduses 'ohtralt', 'piisavalt', mis oli aluseks värvingupartikli küll kujunemisele sarnaselt saksakeelse partikliga wohl. Ilmselt on siin tegu kasutusmalli kopeerimisega. Ka kahe teisegi eestikeelse partikli hästi ja õieti partiklistumist on ilmselt toetatud saksa keel.

\subsection{Partikkel ja}

Partikli ja kasutamisest annab ettekujutuse näide (24). Partikkel jo, millest on kaasaegses kõnepruugis saanud peamine saksakeelse partikli doch vaste eesti keeles, väljendab ühist teadmist, kinnituse otsimist, ka reaktsiooni eelnevale lausungile (vrd Kärk 2010a). Kõneleja on veendunud öeldava õigsuses (antud juhul selles, et kui kuulaja kristlikke eluviise ei järgi, tabab teda õnnetus) ja püüab ka kuulajat seda uskuma panna.

(24) Se pahandus peap jo tullema / doch hedda ninck waiw sel Jnnimessel / kenne lebbi pahandus tullep : Erranis eth meije temma kinni hackame / temma piddame / ninck temma sisse üsckume / eth ep meije hebbex sahme.

Es muß Ja Ergerniß kommen / doch wehe dem Menschen / durch welchen Ergerniß kommet : Sondern das wir jhn ergreiffen / vns an jhn Rom . 10 . 11. halten / vnd gläuben / damit wir nicht zu schanden werden. (HH 1641: 104)

Arvo Laanesti andmetel on sidesõna ja eesti keeles germaani laen (Laanest 1981: 292). Saksa keeles saab partikkel ja esineda vähemalt viies funktsioonis:

1) vastuse- ja nõustumist väljendava partiklina;

2) ühise teadmise, evidentsuse signaliseerijana;

3) üllatuse väljendajana;

4) emfaatilise partiklina nt käsklausetes (Fritz 2005: 218);

5) tähenduses 'isegi' fokuseeriva partiklina nimisõnafraasi, verbi või adjektiivi ees (Helbig 1994: 169). 
Gerd Fritzi (2005: 219-225) andmetel on ja vastusepartiklina olemas juba vanaülemsaksa keeles (600-1100), esinedes kõigis germaani keeltes. Partikli ja kasutamine on mitmekesine. Näiteks võis lausealguseline ja olla vokatiivses tähenduses vaadeldav vastena ladina keele $o$-le $(\mathrm{Ja} d u$ truhten / Oh du Herr / 'O Jumal'); partiklit ja kasutati intensiivistavas funktsioonis (Ja unio henig taz uuas / Ja, wie schrecklich war das / 'Ja kui kohutav see oli') ning ühise teadmise tähistajana; lisaks nimetatutele esines ja ka vastusepartiklina. Keskülemsaksa keeles (1100-1350) lisandub partiklile ja veel vähemalt üks kasutusviis - ülivõrde tähistajana kindla fraasi ees. Seega võib rääkida intensiivistava ja fokuseeriva partikli funktsioonist (er ist heilig / ja der aller heiligest 'ta on püha/isegi kõige püham’3). Kuigi semantiliselt esines nii vana- kui ka keskülemsaksa keeles tänaste värvingupartiklitega sarnaseid kasutusviise, võib alles alates 16. sajandist täheldada värvingupartiklile tüüpilist esinemist lause keskel. Mil viisil ja põhjusel värvingupartikkel lause keskele liikus, ei ole teada. Fritz rõhutab värvingupartiklite ja ning doch vastupidist ajalugu ja eeldab värvingupartikli funktsiooni ülekandumist partiklilt doch partiklile ja:

Die Partikeln ja und doch, die in ihren Verwendungen als Dialogpartikel und Modalpartikel heute eng verwandt sind, haben interessanterweise gerade in diesen Verwendungsweisen eine gegenläufige Geschichte. Doch zeigt schon im Althochdeutschen eine Verwendung, die zumindest eng mit heutiger Modalpartikelverwendung verwandt ist. Da es für andere Partikel diese Verwendungen erst später gibt, kann doch als der frühe Prototyp der Modalpartikelverwendung gelten, der als Präzedenz für Modalpartikelverwendungen anderer Partikel, z.B. von ja dienen konnte. (Fritz 2005: 233)

Pöördume taas Stahli partiklikasutuse juurde (saksakeelse partikli ja vasted eesti keeles on koondatud tabelisse 6).

Stahlil esineb partikkel ja vastusepartikli (näide 25) ja lausealguselise partiklina (26) paralleelselt mõlemas keeles. Sidesõnana, saksakeelse

$3 \quad$ Autori tõlked. 
und vastena kasutab Stahl eesti keeles sõna ninck. Lausealguselisel ja-1 võiks olla mitu tähendust. Kuna kirjavahemärke ei kasutatud, siis eraldas lausealguline ja mõtteid ning kandis lisaks religioossetes tekstides tänaseni säilinud tähendust 'amen, ehk nii see on, see on tõde'. Ainult ühel korral kasutab Stahl saksakeelse partikli ja vastena eesti keeles töddest, töddest (27).

(25) On sulle nüdt se mehl / ninck mötte / sihs ütle: Ja / Jumala nimmet. Jst nu das ewer Will vnd meinung / so sprechet: Ja. (HH 1632: 31)

(26) Ja minna Vsckun / miña ollẽ üx pattune Jnnimeñe.

Ja ich glaube es / ich bin ein Sünder. (HH 1632: 11)

(27) --- meije peame kindlast usckma / eth se Jssa Taiwas meije palwe heldest on wasto wotnut / ninck kuhlnut: Sest tema issi on meile kescknut palluma / ninck towotanut / eth tem a meid tahap kuhlma / Amen / Amen / se on / töddest / töddest / se peap ninda sündima.

--- wir sollen gewiß seyn / der Vater im Himmel habe vnsere bitte gnädiglich angenommen / vnd erhöret: Denn er selber hat vns geboten zu beten / vnd verheissen / daß er vns wolle erhören / Amen / Amen / das heist / ja / ja / es sol also geschehen. (LS 1641: 497)

Värvingupartikkel ja on Stahli kirjapandus kas ilma eestikeelse vasteta (28) või esineb eesti keeles värvingupartikkel jo (29).

(28) Sinna ollet münd errn lunnastanut pattust / surmast / kurratist / ninck pörgkust / omma werre kahs münd maxnut / sedda minna kindlast ussun / minck perrast peaxin minna sihs hend heitma / se surma / ninck pörgko seltzi ehs / eth münna sünno pehl lotan / ollen minna üx önnis laps.

Du hast mich ja erlöset / von Todt / Sünd / Teuffel vnd Höll : Es hat dein Blut gekostet / drauff ich mein Hoffnung stell / warumb solt mir den grawen / fürm Todt vnd höllischen gsind / weil ich auff dich thu bawen / bin ich en selig Kind. (HH 1637: 152)

(29) Minna pallun sünd / sinna wegkiw üllewoija keickest Wainlasest / eth sinna jo tahat / keick Jnnimesset peawat önsax sahma / sinna tahaxit 
Armo andma / ninda kudt minna ristitut ollen / eth minna kahs ninda ussun / ninck lebbi se Vscko se igkawesse Ello sahn.

Jch bitte dich / du mächtiger Vberwinder aller Feinde / weil du ja wilt / alle Menschen sollen selig werden / du wollest Gnade geben / wie ich getaufft bin / daß ich auch also gläube / vnd durch den Glauben das ewige Leben erlange. (LS 1641: 532)

Blume kasutab mõlemas keeles partiklit ja nii lausealguselise kui värvingupartiklina, kuigi mõnel juhul esineb ka eestikeelne partikkel jo (30).

(30) Seperrast on jo meije Kohus Jummala Sanna nink Catechismusse jerrel nende pehle Kochto moistma oppeda / kennelle öike JUmmal on nink temma Nimmi öikest prukiwat nink kumbat sedda mitte teggewat.

Darum will uns ja gebüren nach Gottes Wort nndden Catechismus / di jenigen urteilen zu lernen / welche den rechten GOtt haben und seinen Namen recht brauchen und welche solches nicht tuhn. (Bl 1662: 107)

Muutus toimub taas Helle tekstis, kes eristab ühendavat sidesõna ja ja kasutab lause alguses jaatussõna jah (31). Lausealguseline ja jääb eesti keeles vasteta (32).

(31) Jah rahwas! olleks teil se öige usk, siis teie olleksite öiged ristiinnimessed; sest se teeb meie süddame puhtaks, parrandab sedda, sullatab sedda ueste ümber, annab meile ue mele, ue moistusse, ja teeb meid ueks lomaks.

Ja, lieben Leute, hättet ihr den Glauben, so wäret ihr auch wahre Christen, denn derselbe macht unser Hertz rein, bessert es, schmeltzet es von neuen um, giebt uns einen neuen Sinn, neuen Verstand, und macht uns zu neuen Creaturen. (AzES 1732: 378)

(32) Isse luggu on nendega.

Ja das ist gantz ein anders mit ihnen. (AzES 1732: 380)

Lausesisesel partikli funktsioonis ja kasutamisel ei saa eesti keeles välja tuua reeglipära, sest Helle jätab partikli lihtsalt kasutamata (33) või kasutab partikleid kül (34), küllab (35) ning jo (36). 
(33) Üks keik, kus nemmad söwad, koddo ehk wöljas.

Das ist ja gleich viel, wo sie essen, zu Huasz oder anderswo. (AzES 1732:380)

(34) Kes sedda öölnud? Ei teie kül pole ellades sedda minno suust kuulnud, ei ei pea tööd teggema.

Wer hat das gesagt? Ihr habts ja auch niemaln von mir gehört, daß man nicht arbeiten solle. (AzES 1732: 376)

(35) Küllab siis otse mönnusad sannad saab selle ue Testamenti ramato sees luggeda.

Solchergestalt wird man ja recht köstl. Worte in dem Neuen Testament zu lesen bekommen. (AzES 1732: 386)

(36) Kas siis södima teid ka petnud? Se annab jo ikka häid linno.

Hat denn das Dresch-Land euch auch betrogen, das pfleget ja immer guten Flachs zu geben. (AzES 1732: 389)

Märkimisväärsete erinevustena tuleb Helle kirjasõnas esile tõsta üleminekut sidesõna ja kasutamisele sidesõna ning asemel ja lausealguselise, eraldava, esiletõstva partikli ja kasutamise olulist vähenemist. Käesoleva uurimuse põhiteemaks olevat värvingupartiklit ja kasutab Helle saksa keeles vähe, eesti keeles on täheldatav erinevate omakeelsete vastete kasutamine. Kui Stahl ja Blume värvingupartiklid olid saksa- ja eestikeelses lauses süntaktiliselt enamjaolt samas positsioonis, siis Helle lausestus on oodatult vabam ja eestipärasem.

Lõpetuseks kõrvalepõikena Helle kiidusõnad omaaegse nooruse aadressil, kes lugeda mõistab ja ei pea mitte "nagu puuklots" raamatuta kirikus seisma (37). Tegu on ilmeka näitega sellest, et noored omandasid saksapärasema kirjakeele ja see levis.

(37) Kül nääksime, agga ei woi parrata; meil on kül halle meel nähha kirrikus, et norel rahwal igga ühhel ramat käes, ja meie seisame kui wannad pu-kandid.

Freylich mögte man es wol wünschen, allein es steht nicht mehr zu ändern; unser Hertz wird in der Kirchen mannichmal bewegt, wenn wir sehen die Jugend, wie ein jeglicher sein Buch in der Hand hat, und wir stehen da als alte Klötze. (AzES 1732: 383) 


\begin{tabular}{|c|c|c|c|c|}
\hline 荥 & $\begin{array}{l}\text { वे } \\
\underset{y}{10}\end{array}$ & $\underbrace{\frac{0}{0}}_{0}$ & 1 & 1 \\
\hline 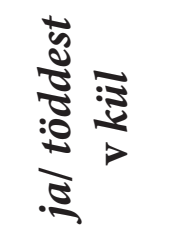 & 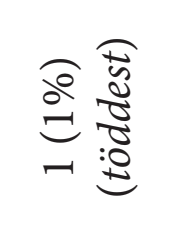 & 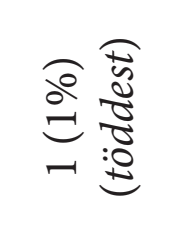 & 1 & 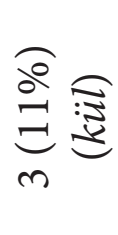 \\
\hline 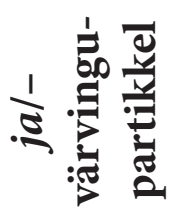 & 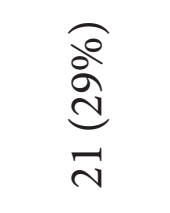 & 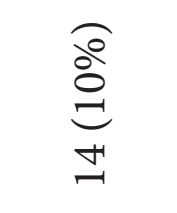 & $\begin{array}{l}\text { वे } \\
\text { in } \\
-1\end{array}$ & 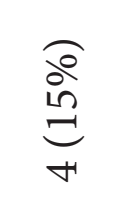 \\
\hline 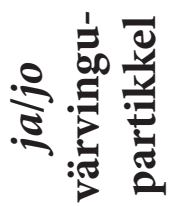 & 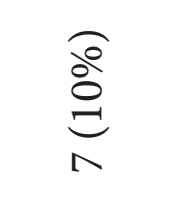 & 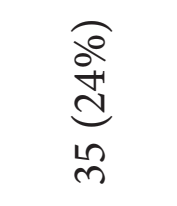 & 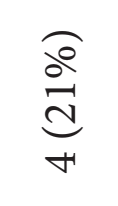 & 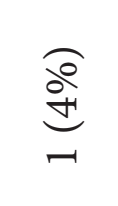 \\
\hline 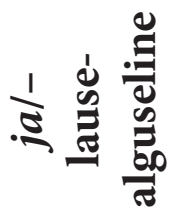 & 1 & 1 & 1 & $\begin{array}{l}\overbrace{0}^{a} \\
\hat{n}_{0}^{n}\end{array}$ \\
\hline 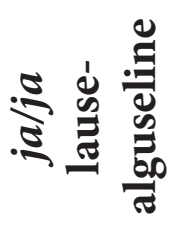 & 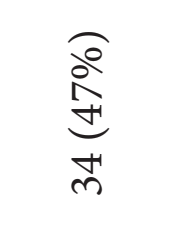 & 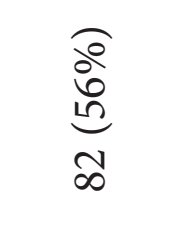 & $\begin{array}{l}\overbrace{0}^{0} \\
0 \\
0 \\
0\end{array}$ & 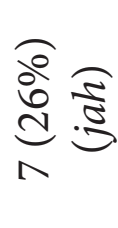 \\
\hline 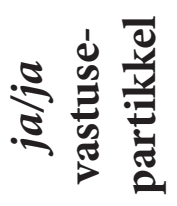 & $\underbrace{\frac{\widehat{Q}}{\infty}}_{0}$ & $\underset{+}{\stackrel{0}{0}}$ & $\begin{array}{l}\text { ae } \\
10 \\
1\end{array}$ & $\underbrace{\stackrel{\partial}{d}}_{\sim}$ \\
\hline$\frac{\vec{y}}{\tilde{H}}$ & 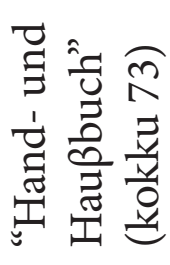 & 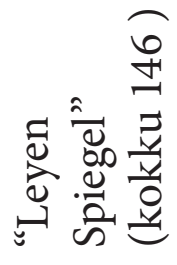 & 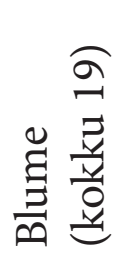 & 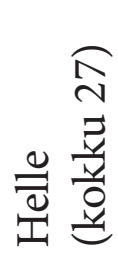 \\
\hline
\end{tabular}




\section{Kokkuvõtteks}

17.-18. sajandi eesti-saksa paralleeltekstide võrdlemine partiklikasutuse seisukohast lubab teha mitmeid oletusi (värvingu)partiklite väljakujunemise, kasutusvõimaluste ja sõnalaenude kohta. Siinne uurimus keskendus kolme saksakeelse partikli doch, wohl ning ja kasutamise võrdlusele nende eestikeelsete ekvivalentidega .

Vanemates, 17. sajandist pärit Stahli ja Blume tekstides kasutatakse valdavalt saksakeelsete värvingupartiklite vastetena eestikeelseid partikleid samas lausepositsioonis, erandina tuleb esile tuua saksakeelse värvingupartikli doch kasutamist 17. sajandi eesti kirjakeeles. Vaatamata ohtrale kasutamisele ei ole doch muutunud laensõnaks, kuna hilisemates kirjalikes allikates, sh murdesõnavaras, saksakeelne partikkel doch puudub. Partikli doch vastetena oli vanemas eesti kirjakeeles kasutusel doch, siiski, ometi, õieti, partikli wohl vastetena kül, küllab ning partikli ja vastena eestikeelset partiklit jo, mis lubab oletada, et nimetatud partiklid olid eesti keeles kasutusel. Vastete olemasolu saksakeelsetele partiklitele annab ühest küljest tunnistust sellest, et tolleaegsed kirjamehed pidasid värvingupartiklite tõlkimist oluliseks, mis omakorda avaldas mõju partiklite kasutamisele eesti keeles. Vaatamata Helle 18. sajandist pärit tekstide eestipärasemale süntaksile on partiklid eesti keeles valdavalt jäänud samaks.

Kokkuvõtteks võib väita, et värvingupartiklid on omakeelsed, kuid nende kasutamisel on ilmselt tegemist malli kopeerimisega, saksakeelse partiklikasutuse ülekandmisega eesti keelde.

Etümoloogiliselt on saksa keeles analüüsitud partiklitest vaid doch olnud kasutusel värvingupartiklina enne aastat 1600 ning tõenäoliselt olnud edaspidi malliks peamiselt adverbide kasutuselevõtul värvingupartikli funktsioonis. Eesti keeles võib nii mõnegi partikli puhul täheldada sarnast kujunemislugu. Partiklipaari wohl - kül võrdlemine lubab oletada, et sarnaselt saksakeelse adverbi wohl lisafunktsiooni tekkimisele värvingupartiklina, on ka eestikeelne partikkel kül kujunenud kommunikatiivsel tasandil adverbi 'küllalt', 'piisavalt' erifunktsiooniks. Sarnaselt 
partiklile doch ei ole aset leidnud otsest laenamist, küll aga on märke saksa keelele omase kasutuse kopeerimisest.

Kõige huvitavama arengulooga kolmest vaatluse alla võetud partiklist on saksa keele partikkel ja, mille oluliseks semantiliseks komponendiks on 'ühine teadmine'. Siinkohal on Stahl osanud kasutada nüüdseks murdelist partiklit jo (ju), mis on ilmselt kujunenud adverbi juba, ju erifunktsiooniks. Võib oletada, et ka sõnade hästi, õieti, tõesti partiklistumisele on saksa keel kaasa aidanud.

17.-18. saj eesti kirjakeeles on saksakeelsete partiklite doch, wohl ning ja vasted järgmised:

- doch - doch, sihskit, sihski, ommeti, kül;

- $\quad$ wohl - hehste, heste, kül, kühl, küllab, öigkest, önis, öiete;

- ja-ja, jo, kül, töddest.

Analüüsitud tekstide põhjal võib väita, et (värvingu)partiklid on omakeelsed, kuid nende kasutamisel on eeskujuks olnud saksa keel.

\section{Tänusõnad}

Artikli valmimist on toetanud Eesti Teadusfondi grandid nr 8304 "Baltisaksa kultuuritekstid ja (post)koloniaalne diskursus", nr 7824 "Kultuurikontaktid ja autobiograafiline diskursus 17. sajandil" ja nr 9026 "Kultuurikontaktid ja nende kajastamine varase uusaja (oma)eluloolistes tekstides". Autor on tänulik kahele anonüümsele retsensendile põhjalike kommentaaride eest.

\section{Kirjandus}

DUDEN 4. 1966, 2009. Grammatik der deutschen Gegenwartssprache. Mannheim.

DUDEN 7. 1989. Das Herkunftswörterbuch. Mannheim.Eisenberg, Peter 1985. Grundriß der deutschen Grammatik. 3., überarbeitete Auflage. Stuttgart Weimar: Metzler.

EKSS = Eesti kirjakeele seletav sõnaraamat. www.eki.ee/dict.ekss (18.07.2012).

Fritz, Gerd 2005. Einführung in die historische Semantik. Tübingen: Niemeyer.

Habicht, Külli 2009. Heinrich Stahli eripärased modaaladverbid. - Keel ja Kirjandus 8-9, 608-619. 
Helbig, Gerhard 1994. Lexikon deutscher Partikeln. Leipzig: Langenscheidt.

Helbig, Gerhard, Joachim Buscha1996, 2001. Deutsche Grammatik. Ein Handbuch für den Ausländerunterricht. Leipzig: Langenscheidt.

Helle, Anton Thor 2006. Lühike sissejuhatus eesti keelde 1732. Saksa keelest tõlkinud ja järelsõna kirjutanud Annika Kilgi ja Kristiina Ross. Tallinn: Eesti Keele Sihtasutus.

Hennoste, Tiit 1997. Eesti keele sotsioperioodid. Üldpilt. - M. Erelt, M. Sedrik, E. Uuspõld (Toim.). Pühendusteos Huno Rätsepale. Tartu Ülikooli eesti keele õppetooli toimetised 7. Tartu: Tartu Ülikooli Kirjastus, 45-66.

Hennoste, Tiit 2000. Sissejuhatus suulisse eesti keelde. IV Suulise kõne erisõnavara. III partiklid. - Akadeemia 8, 1772-1806.

Hennoste, Tiit 2002. Suulise kõne uurimine ja sõnaliigi probleemid. - R. Pajusalu, I. Tragel, T. Hennoste, H. Õim (Toim.). Teoreetiline keeleteadus Eestis. Tartu Ülikooli üldkeeleteaduse õppetooli toimetised 4. Tartu: Tartu Ülikool, 56-73.

Hentschel, Elke 1986. Funktion und Geschichte deutscher Partikeln. Ja, doch, halt und eben. Tübingen: Niemeyer.

Hentschel, Elke, Harald Weydt 1994. Handbuch der deutschen Grammatik. 2. Auflage. Berlin: Walter de Gruyter.

Karsten, Rinas 2007. Tschechische Abtönungspartikel - Entlehnung aus dem Deutschen oder autochthone Entwicklungen? - Brücken - Germanistisches Jahrbuch Tschechien-Slowakei 15, 389-404.

Kärk, Janika 2010a. Funktionen von Abtönungspartikeln. Die Partikel doch und ihre Entsprechungen in der estnischen Sprache. - Triangulum. Germanistisches Jahrbuch für Estland, Lettland und Litauen, 97-109.

Kärk, Janika 2010b. Värvingupartiklid eesti- ja saksakeelsetes küsilausetes. Eesti Rakenduslingvistika Ühingu aastaraamat 6, 121-134. http://dx.doi. org/10.5128/ERYa6.08

Kärnä, Aino 2005. Ein altes Problem: Partikeln in der Grammatik - ja, aber wie? Linguistik online 22, 1/05. http://www.linguistik-online.de/22 05/kaernae.html (18.07.2012).

Laanekask, Heli 2004. Eesti kirjakeele kujunemine ja kujundamine 16.-19. sajandil. Dissertationes philologiae estonicae Universitatis Tartuensis 14. Tartu: Tartu Ülikooli Kirjastus.

Laanest, Arvo 1981. Einführung in die ostseefinnische Sprachen. Hamburg: Buske Verlag.

Lill, Anne 1988. Christoph Blume ja XVII sajandi eesti kirjakeel. - Keel ja Kirjandus 2, 90-102. 
Lotman, Piret 2010. Heinrich Stahli pastoraalne tegevus Rootsi Läänemere provintsides 17. sajandi esimesel poolel. Dissertationes theologiae Universitatis Tartuensis 20. Tartu: Tartu Ülikooli Kirjastus.

Lütten, Jutta 1979. Die Rolle der Partikeln 'doch', 'eben' und 'ja' als KonsensusKonstitutiva in gesprochener Sprache. - H. Weydt (Hrsg.). Die Partikeln der deutschen Sprache. Berlin: Walter de Gruyter, 30-38.

Mägiste, Julius 2000. Estnisches Etymologisches Wörterbuch IV. 2. Auflage. Helsinki: Finnisch-Ugrische Gesellschaft.

Ross, Kristiina 2008. Joobelist ja juubelist - Anton Thor Helle 325. - Keel ja Kirjandus 10, 753- 759 .

Ormelius-Sandblom, Elisabet 1997. Die Modalpartikeln ja, doch und schon. Zu ihrer Syntax, Semantik und Pragmatik. Stockholm: Almqvist \& Wisell.

Thurmair, Maria 1989. Modalpartikeln und ihre Kombinationen. Tübingen: Niemeyer.

Weydt, Harald 1979. Partikelalanyse und Wortfedmethode: doch, immerhin, jedenfalls, schließlich, wenigstens. - H. Weydt (Hrsg.). Die Partikeln der deutschen Sprache. Berlin: Walter de Gruyter, 395-413.

\section{Janika Kärk}

Tallinna Ülikooli eesti keele ja kultuuri instituut

Narva mnt 25

10120 Tallinn, Estonia

janika.kark@mail.ee 


\title{
About the development of modal particles: Estonian equivalents of German particles doch, wohl and ja
}

\author{
JANIKA KÄRK \\ Tallinn University
}

The comparison of Estonian and German parallel texts from the 17th and 18th centuries with a view to exploring the use of particle words enables us to make several assumptions about the formation, deployment and borrowing of (flavouring) particles as a word class. This research will focus on the comparison of the German particles $j a$, doch and wohl with their Estonian equivalents in the works of Heinrich Stahl, Christoph Blume and Anton Thor Helle. Of these particles, only doch was used in German as a modal particle before the year 1600, and it probably influenced the further introduction of (mainly) adverbs in modal particle function. Although the use of the German particle doch in Estonian language texts was common in the older texts of Stahl and Blume dating from the 17th century, we may also find a few Estonian equivalents like siiski, ometi, õieti, allowing to assume that these particles were used in Estonian. It seems that the German doch had no direct impact on the use of particles in Estonian, proved by the fact that a hundred years later Helle gave up using the particle doch in his Estonian texts. Rather, it may have been common practice to transfer German particle usages into Estonian. However, Stahl, Blume and Helle could not find an Estonian equivalent for one specific shade of the particle doch, namely common or shared knowledge, although all of them must have known the particle jo, which was used in the abovementioned meaning as an equivalent of the German particle $j a$. Of the three particles under discussion, the most interesting is the development of the German particle ja, whose important semantic component is again common knowledge. In that case Stahl knew how to use the currently dialectal particle jo $(j u)$, which had obviously assumed a special function of the adverb juba, ju. Hence, based on the current research, we may presume that the existence of (modal) particles in Estonian is an inherent quality of the Estonian language.

Keywords: German influence on the Estonian language; loan words; modal particles; Estonian; German 